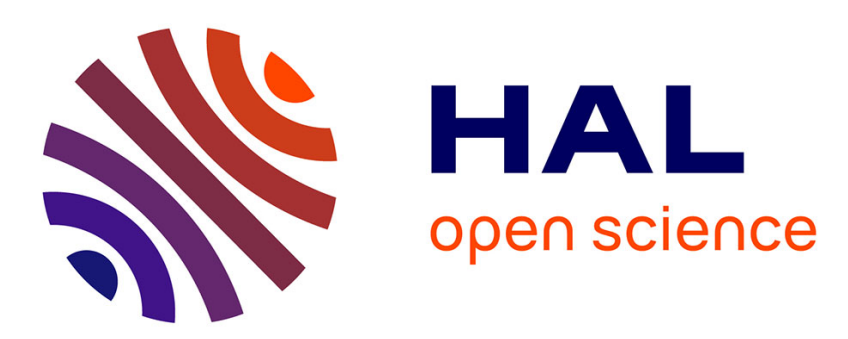

\title{
Application of an aerodynamic code to marine propellers
}

\author{
M. Schaffar, J. Haertig
}

\section{To cite this version:}

M. Schaffar, J. Haertig. Application of an aerodynamic code to marine propellers. Journal de Physique IV Proceedings, 1994, 04 (C5), pp.C5-989-C5-992. 10.1051/jp4:19945217 . jpa-00252902

\section{HAL Id: jpa-00252902 https://hal.science/jpa-00252902}

Submitted on 1 Jan 1994

HAL is a multi-disciplinary open access archive for the deposit and dissemination of scientific research documents, whether they are published or not. The documents may come from teaching and research institutions in France or abroad, or from public or private research centers.
L'archive ouverte pluridisciplinaire HAL, est destinée au dépôt et à la diffusion de documents scientifiques de niveau recherche, publiés ou non, émanant des établissements d'enseignement et de recherche français ou étrangers, des laboratoires publics ou privés. 


\title{
Application of an aerodynamic code to marine propellers
}

\author{
M. SCHAFFAR and J. HAERTIG
}

French-German Research Institute, 5 rue du Général Cassagnou, 68301 Saint-Louis, France

\begin{abstract}
The vortex lattice method successfully applied in the past to helicopter rotors is now applied to marine propellers. Two cases are presented: advancing coefficient .7 with uniform and non-uniform upstream velocity behind a vortex generator. The results presented here concern the evolution of the thrust coefficient with the azimuth angle, the spanwise distribution of the thrust and the wake.
\end{abstract}

\begin{tabular}{|c|c|c|c|}
\hline \multicolumn{2}{|c|}{ Notation } & $\begin{array}{l}U_{\infty}, U_{z} \\
x, y, z\end{array}$ & $\begin{array}{l}\text { velocity of the upstream flow } \\
\text { coordinate system }\end{array}$ \\
\hline D & propeller diameter & $\beta_{j}^{k}$ & circulation shed in the wake \\
\hline$K_{T}$ & thrust coefficient & $\Gamma, \Gamma r_{, j}, \gamma_{n_{j}}$ & panel bounded circulation \\
\hline 了 & advancing coefficient & $\varphi$ & perturbation potential \\
\hline N & total panel number & $\psi$ & azimuth angle \\
\hline$R$ & propeller radius & $\Omega$ & angular rofational velocity \\
\hline
\end{tabular}

\section{Introduction}

Rotor blade/vortex interaction (BVi) noise is one among several noise sources for helicopters during low speed or landing flight. Since three years we have developed an aerodynamic code named ROTAR, in order to compute the loads on the rotor blades $[1,2,3,4]$ which serve as input data for an acoustic code named ROTAC for the noise prediction.

With the support of the DRET an attempt is made to apply this aerodynamic code to marine propellers. The aerodynamic code is based on incompressible and inviscid flow, what is also the case in water flow. Nevertheless some particular phenomena like cavitation can not be simulated in the code. The propeller data and the testing conditions were obtained from the DCN $[5,6]$ and it is planed to compare our results with other computed results and also with experimental results. 
In this paper we present a description of the method and the first results obtained for a 4 bladed propeller.

\section{Description of the computational method (ROTAR Code)}

Using Green's theorem, the solution of the Laplace equation for the perturbation potential $\varphi$ leads to a sources and doublets distribution on the blades and doublets on the wake; for thin blades only the doublets distribution is necessary; in our case, for each panel, we use the equivalence between a constant surface doublet and peripherical vortex lines.

The following system of axis is chosen (see figure 1): $z$ is the vertical axis and corresponds to the axis of the propeller $\left(U_{\infty}=-1\right.$.) and $x, y$ is an horizontal plane in which the propeller is rotating.

Each of the blades is divided into $N=N_{x} \cdot N_{y}$ quadrilateral panels ( $N_{x}$ chordwise, $N_{y}$ spanwise, see figure 2). On this panel system, we map a bound vortex lattice with vortex lines of the strength $\Gamma_{r_{1}}$ in the spanwise direction (figure 1) and vortex lines in the chordwise direction whose strength $\gamma_{\mathrm{r}, \mathrm{j}}$ is defined by $\gamma_{\mathrm{i}, \mathrm{j}}^{\mathrm{r}}=\sum_{\mathrm{k}=1}^{\mathrm{i}}\left(\Gamma_{\mathrm{k}, \mathrm{j}}^{\mathrm{n}},-\Gamma_{\mathrm{k}, \mathrm{j}}\right)$ where $\mathrm{n}$ indicates the time step. At each time step the conservation of the circulation is warranted by the shedding of an unsteady vortex line $\beta^{n}$; the wake is built stepwise by the vortices previoulsy shed and it is free to move for each time step.

With the non-penetration condition we obtain a system of $N$ linear equations by writing the induced velocities at each control point using the Biot-Savart law. The pressure jump across the blades $\Delta p_{i, j}=-\left(p_{1}-p_{u}\right)_{i, j}$ is obtained with the Bernoulii equation written for the upper $(u)$ and the lower (1) side of the blade. At the end of the time step $n$, the normalized propeller thrust coefficient $K_{T}$ is computed. The computational step is $30^{\circ}$ and 60 steps are sufficient to obtain a steady state.

The Vortex Lattice Method computes the loads for a thin blade and to obtain the loads acting upon thick blade we use for each position in span a conformal mapping to extrapolate the results to a thick blade, assuming that the potential $\varphi$ remains the same.

\section{Application to a 4-bladed propeller}

We present only two cases:

1. advancing coefficient 0.70 with uniform upstream velocity $(0,0,-1$.$) ,$

2. advancing coefficient 0.71 and non-uniform upstream velocity created by a wake generator which simulates the propeller's shaft and supports.

For each case we compute the following quantities:

- the total thrust coefficient $K_{T}$ and the momentum coefficient $K_{Q}$ determined with the pressure forces only, the evolution of the thrust with the spanwise position and the local thrust,

- the tip vortex circulation, 
- the evolution of the normalized circulation with the spanwise position,

- the wake evolution $(z / R, r / R)$ with the azimuth angle behind the blade and the variation of $r / R$ in function of $z / R$,

- the local $\triangle \mathrm{Cp}$ normalized by the free stream velocity,

- the velocities in 4 planes above and below the propeller.

In this short paper we present a small part of these results (see figures 3 to 5 ). The evolution of the thrust coefficient with the azimuth angle shows a rapid convergence to 0.19 for the uniform upstream velocity and to 0.18 (with small oscillations) for the generator's wake (for the momentum coefficient $K_{Q}$ the corresponding values are 0.031 and 0.030 ). The spanwise evolution of the thrust shows a maximum at $.75 \mathrm{R}$, a constant value when the upstream velocity is uniform and some variations with the blade number for the generator's wake.

The two last figures show the evolution of the tip vortex behind the propeller: the variation of the contraction $(z / R)$ in function of the altitude $(z / R)$ shows a straight line over 6 radii when the upstream velocity is uniform and some diverging periodic variations for the propeller moving in the wake behind a generator.

\section{Concluding remarks}

These calculations will continue with taking into account the central body on which the propeller is fixed. The last step will be the comparison with experimental results and with results obtained by other computational methods.

\section{Acknowledgment}

This work is conducted with the support of the DRET (contract 92/1246A)

\section{Bibliography}

1. M.Schaffar, J.Haertig and P.Gnemmi, Aerodynamic loads and blade/vortex interaction noise prediction, 15th European Rotorcraft Forum, Paper 3, Amsterdam, Netherlands, 12-15 Sept. 1989

2. M. Schaffar, J. Haertig and P. Gnemmi, Computation of the BVI noise for the BO105 model rotor in forward flight and comparison with wind tunnel tests, 47th AHS Forum, Phoenix, Arizona, USA, 5-7 May 1991

3. J. Haertig and P. Gnemmi, Calcul du bruit d'épaisseur et du bruit de charge rayonnés par un rotor en vol d'avancement, ISL-Report R 119/89, Saint-Louis, France

4. M. Schaffar, J. Haertig and P. Gnemmi, Interaction pale/sillage sur un rotor bipale avec prévision du bruit rayonné (vol stationnaire et vol d'avancement, comparaison calcul/expérience), ISL-Report R 120/89

5. J.P. Béguier, Workshop hélice: données pour les codes de calcul, Bassin des Carènes, No. 3.2.97.2421, Janvier 1993

6. J.P. Béguier, Workshop Hélice: additif aux données pour les codes de calcul, Bassin des Carènes, No 3.2.97.2443, Avril 1993 


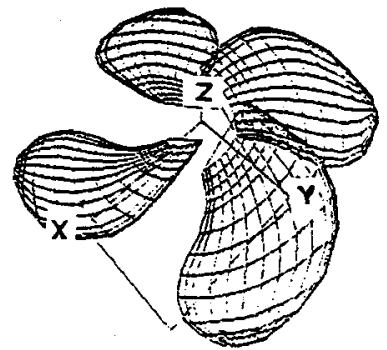

Fig. 1: Propeller axis: $x, y \geq$ (vertical = upstream)

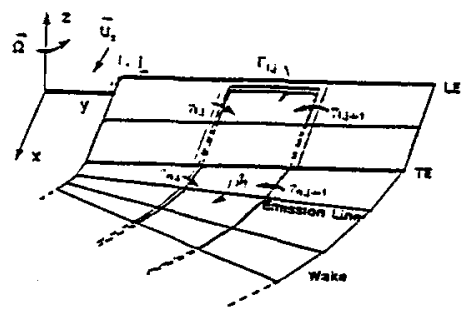

Fig. 2: Vortex Lattice on the blade
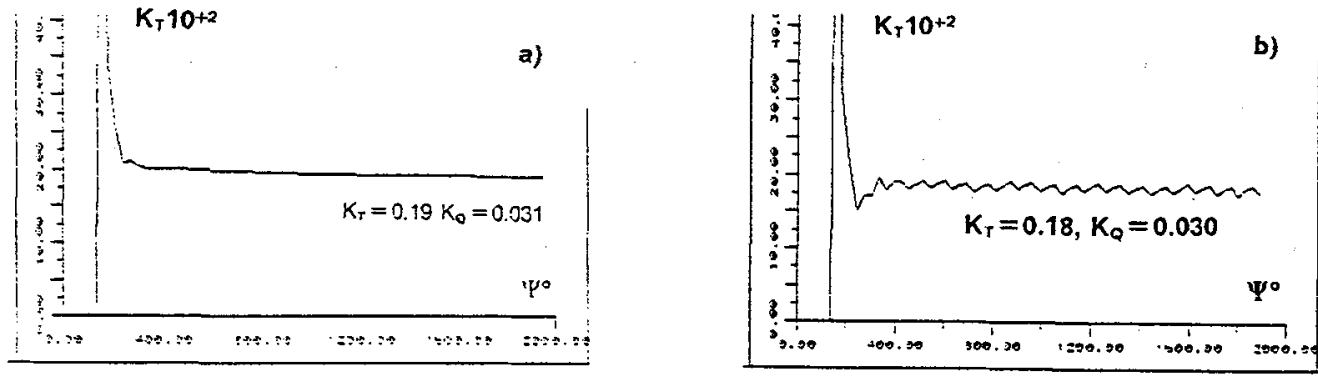

Fig. 3: Evolution of the thrust coefficient $\left.K_{T}: a\right)$ uniform upstream velocity, b) non-uniform upstream velocity.
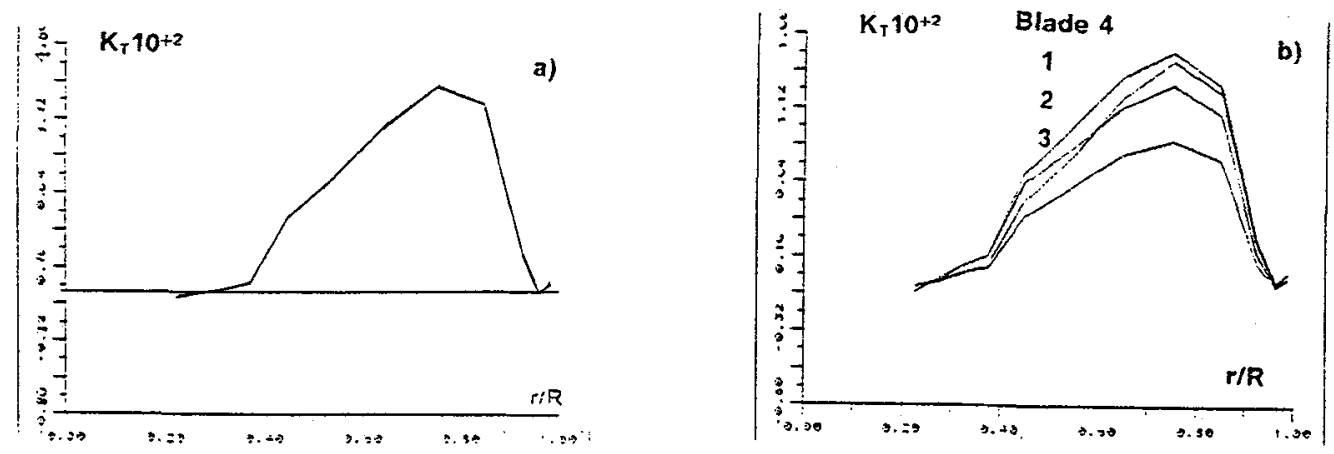

Fig. 4: Spanwise evolution of the thrust: a) uniform upstream velocity, b)non-uniform upstream velocity.
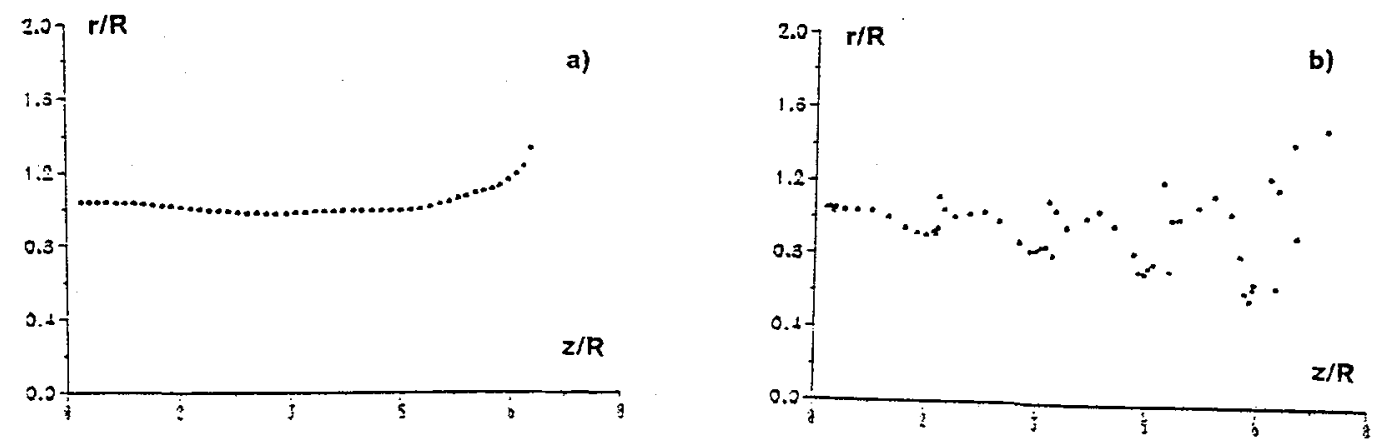

Fig. 5: Wake behind the propeller: contraction $(r / R)$ in function of the altitude $(z / R)$. 